\title{
Carotid baroreceptor activation therapy for resistant hypertension and heart failure: a report of two cases
}

\author{
Ahmet Baris Durukan, Hasan Alper Gurbuz \\ Department of Cardiovascular Surgery, Medical Park Usak Hospital, Usak, Turkey \\ Kardiochirurgia i Torakochirugia Polska 2018; 15 (3): 200-203
}

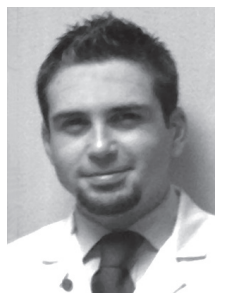

\section{Introduction}

A vast number of drugs and treatment strategies have been approved for treatment of hypertension in the last three decades. However, despite these advances, there is still a reported prevalence of 3 to $30 \%$ of treatment-resistant hypertension (TRH) [1]. According to 2013 ESH/ESC guidelines for the management of arterial hypertension, TRH is defined as an office measurement of systolic blood pressure $(\mathrm{BP})>140 \mathrm{~mm} \mathrm{Hg}$ and/or diastolic BP of $>90 \mathrm{~mm} \mathrm{Hg}$ despite appropriate life-style measures and antihypertensive treatment including a diuretic (at full dose) and two other antihypertensive drugs of different classes at adequate doses [2]. Following catheter-based renal denervation therapy, the concept of TRH has gained popularity and specific therapies have emerged including carotid baroreceptor activation therapy (BAT).

Similar to the concept of TRH, despite enormous advances in surgical and medical treatment of heart failure (HF), 25 to $35 \%$ of cases remain in NYHA class III. These patients often experience moderate to severe heart failure symptoms and have a low quality of life, causing increased health care costs. We already know that adrenergic activation and parasympathetic denervation have a role in symptom occurrence and disease progression [3]. With this rationale, carotid BAT has emerged as a therapeutic strategy in treatment of heart failure.

Here, we report two cases, one with resistant hypertension and the other with heart failure treated with surgical BAT.

Written informed consent was obtained from each patient for submission of the report.

\section{Case reports}

\section{Case 1}

A 52-year-old male patient was being followed up for hypertension for 10 years and TRH was diagnosed one year ago. He had coronary artery disease and type 2 diabetes mellitus. He had a triple vessel bypass 10 years ago and repeat percutaneous coronary intervention $(\mathrm{PCI})$ was performed for left anterior descending artery (LAD) and right coronary arteries in the following years. He was on a $\beta$-blocker and angiotensin receptor antagonist/diuretic combination. His ambulatory blood pressure monitoring (ABPM) record (Ambulatory Blood Pressure Monitor, Model: ABPM50, Contec Medical Systems Co., Ltd, People's Republic of China) revealed a mean systolic BP of $155 \mathrm{~mm} \mathrm{Hg}$ and diastolic BP of $100 \mathrm{~mm} \mathrm{Hg}$ despite therapy. He was scheduled for carotid baroreflex activation therapy (BAT) and surgical insertion was performed successfully. A mean 20/11 and 26/12 $\mathrm{mm}$ Hg decline was recorded on ABPM after 1 month and 3 months respectively.

\section{Case 2}

A 55 year-old male patient was being followed up for ischemic cardiomyopathy. He had an LAD stent which was re-stenosed and stented again 6 months ago concomitant with implantable cardioverter-defibrillator (ICD) implantation. He was in NYHA class III-IV. He was on GDMT ( $\beta$-blocker + angiotensin converting enzyme inhibitor + nitrate + aldosterone receptor antagonist) for HF, but was still symptomatic. Transthoracic echocardiography revealed an ejection fraction of $20 \%$ with an left ventricular end diastolic dimension (LVEDD) of $67 \mathrm{~mm}$ and left ventricular end systolic dimension (LVESD) of $59 \mathrm{~mm}$. He had moderate mitral insufficiency and moderate tricuspid insufficiency. The 6-minute walking test was not performed. He was scheduled for carotid BAT and surgical insertion was performed successfully. After 3 months, he was in NYHA class II. The patient was hemodynamically stable. Echocardiography revealed an ejection fraction of $22 \%$ with an LVEDD of $63 \mathrm{~mm}$ and LVESD of $57 \mathrm{~mm}$. The patient had mild to moderate mitral and mild to moderate tricuspid insufficiency. Echocardiography was performed by same operator. However, objective improvement was documented by the patient's clinical status since the echocardiographic change cannot be statistically evaluated.

The blood pressure values of the patient did not change, but the basal heart rate decreased to $85 \mathrm{bpm}$ from $91 \mathrm{bpm}$ on an office basis with the same medications. 


\section{Surgical procedure}

Under general anesthesia, the patient is positioned as in carotid endarterectomy. General anesthesia is crucial for maintenance of stable hemodynamics and neutralization of external effects. The carotid bifurcation may be marked with ultrasonography if required. A vertical or transverse (as suggested by the manufacturer) incision is performed. The carotid bifurcation is explored only anteriorly. The periadventitial tissues are dissected carefully. Only superficial carotid dissection is performed; extended dissection is not necessary and not suggested. Carotid body manipulation is avoided.

The procedure is continued with the "mapping", where the anesthesia and surgical team should be in synchrony. The target systolic BP should be $>90 \mathrm{~mm} \mathrm{Hg}$ and the heart rate should be $>65 \mathrm{bpm}$. Administering fluids can be considered in order to maintain euvolemia. As a last resort, infusions of phenylephrine/epinephrine/dopamine may be administered, as long as a steady-state response is achieved prior to mapping.

The device has three components: the lead, the battery and the implant adaptor connecting them (Fig. $1 \mathrm{~A}$ ). First, a temporary anode is formed. A 16-18 G needle $\geq 5 \mathrm{~cm}$ long is inserted parallel to the skin into subcutaneous tissues where the Implantable Pulse Generator (IPG) pocket will be. A terminal pin connector is inserted into the IPG header and tightened to set the screws. The alligator clip is inserted on clear/white wire to the lead terminal pin and connected on blue wire to the metal portion of the needle. The implant mapping tool is attached to the lead buckle. The wrench is inserted into the pin set screw and then to the lead or implant adapter (Fig. 1 B) into the IPG header. The port plug is inserted into the IPG header.

Prior to mapping, impedance is checked with an electrode on the vessel to confirm connections. Mapping is conducted with device parameters programmed to $6 \mathrm{~mA}$, 125 us, and 80 pps, but these parameters may be adjusted as necessary to improve the response or avoid extraneous stimulation. Touching the electrode disk directly with any metal instruments during mapping and suturing is avoided. Using the mapping tool, the steady electrode is positioned and held on a given location on the carotid sinus. Then, BP and heart rate stabilization while the IPG is programmed off is allowed. The device is turned on and adequate activation time to determine the hemodynamic response (e.g. $30-60 \mathrm{~s}$ ) is ensured (note that you may need to wait longer (e.g. $3 \mathrm{~min}$ ) in some patients, if the first few sites do not provide a robust response). The device is turned off, maintaining the position of the electrode to look for a rebound effect. These steps are repeated at other locations until an adequate response is observed (Fig. 2, Mapping Loca-

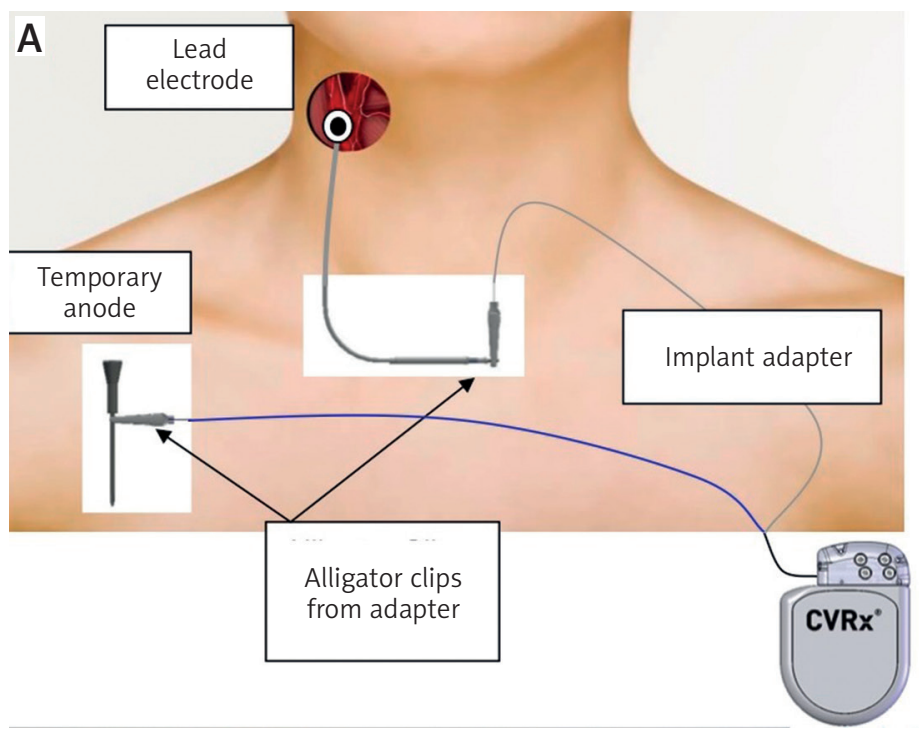

B
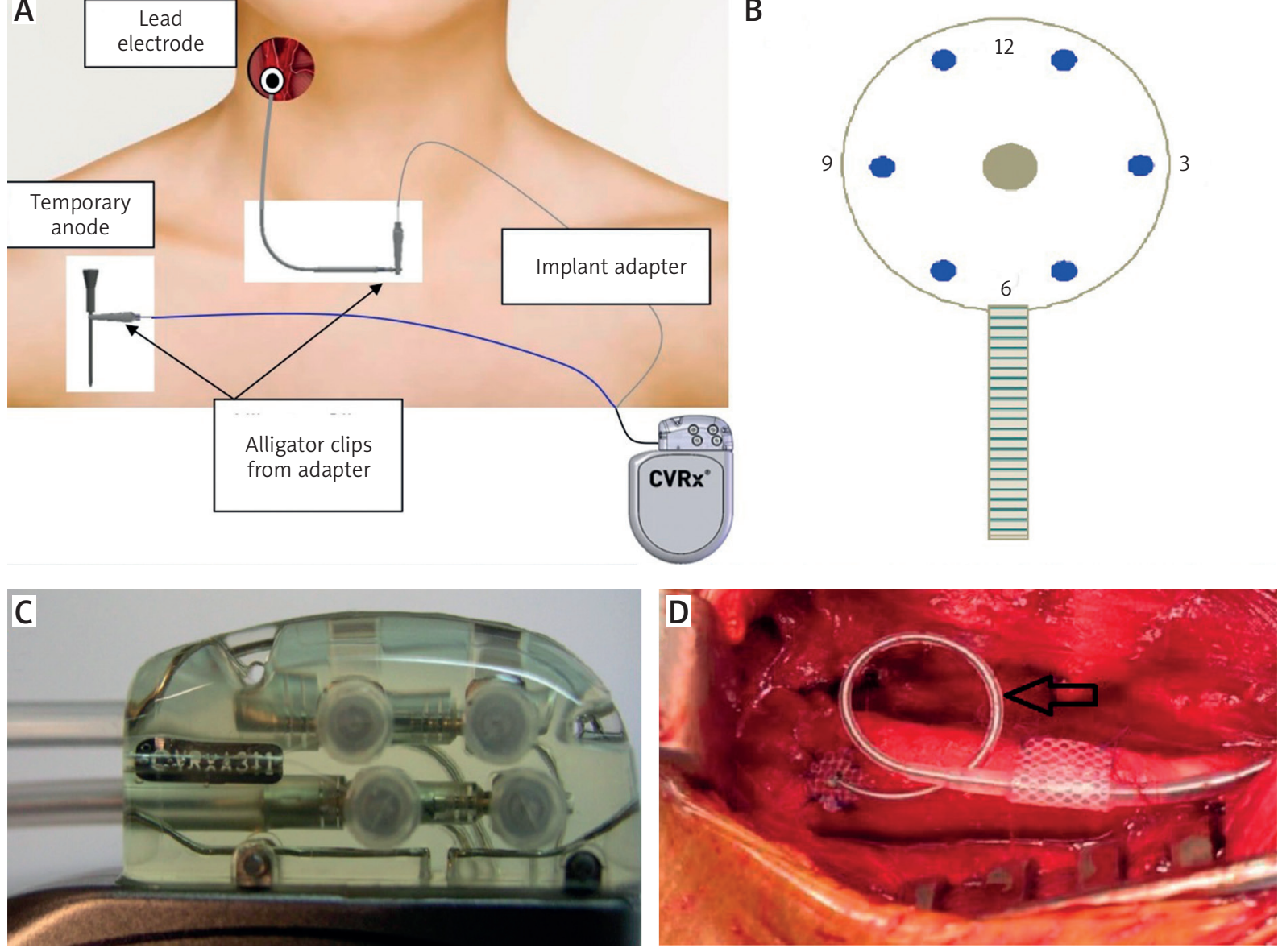

Fig. 1. The carotid baroreceptor activation device: $\mathbf{A}$ - the three components: the lead, the battery and the implant adaptor connecting them, $\mathbf{B}$ - the implant adaptor, $\mathbf{C}$ - electrode suturing sites, D - the strain loop (arrow) 


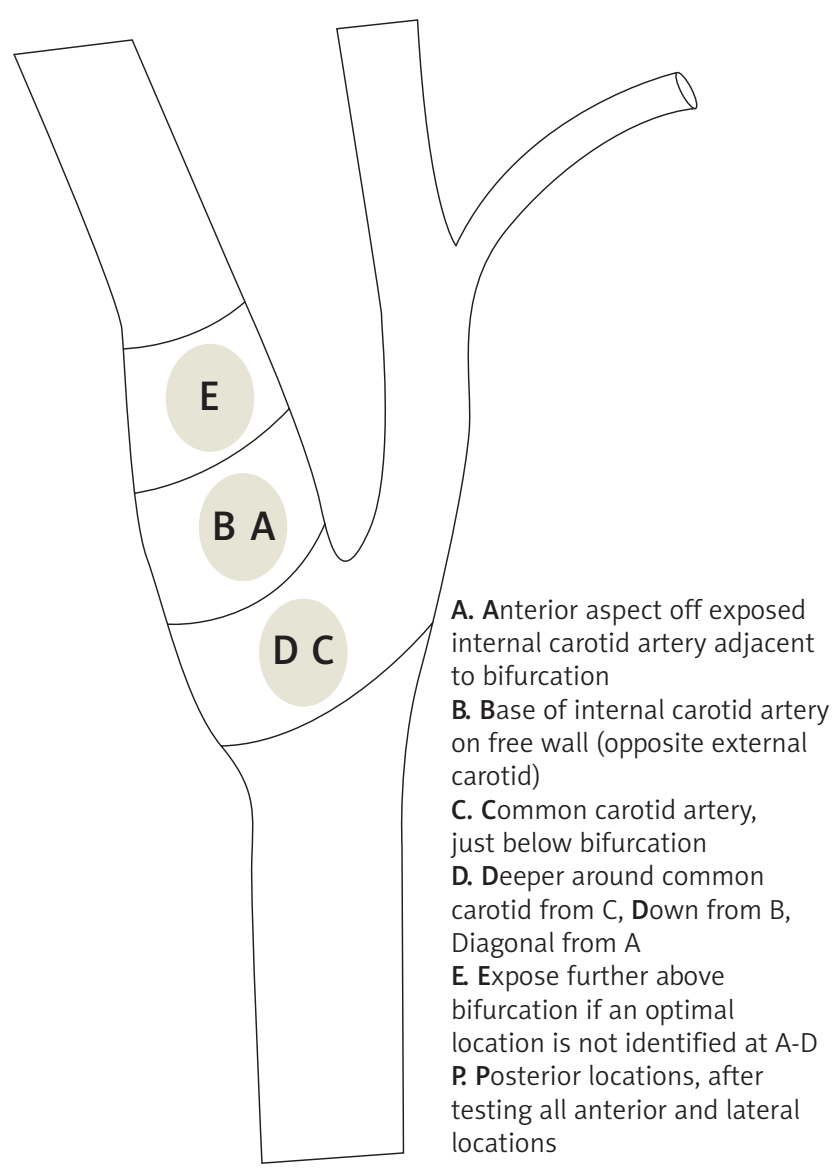

Fig. 2. Mapping locations guide

tions Guide). Excessive changes in hemodynamics during mapping should be avoided; $15-20 \%$ reductions are typically adequate for determining implant location. The electrode is removed from the carotid sinus if the heart rate is $<40 \mathrm{bpm}$, systolic BP is $<90 \mathrm{~mm} \mathrm{Hg}$ and diastolic BP is $<50 \mathrm{~mm} \mathrm{Hg}$. The electrode is sutured to the adventitia as in epicardial pacemaker lead implantation (Fig. 1 C). After the lead is sutured in, the impedance is rechecked. Then the implant adapter is disconnected, the temporary anode (needle) is removed and the IPG is wrapped in gauze soaked in antiseptic solution and set aside on a sterile instrument tray. The IPG pocket is created on the ipsilateral side with the lead. The lead is tunneled and connected to the IPG while a strain relief loop is formed on the carotid artery (Fig. 1 D).

\section{Discussion}

Patients with resistant hypertension constitute a challenging group in treatment of hypertension. These patients are refractory to treatment despite measures. Other nonpharmacologic measures can be considered in this group such as renal denervation. While the SYMPLICITY HTN-1 and HTN-2 trials have gained support and confidence, the SYMPLICITY HTN-3 trial has raised some questions on its real efficacy [4]. An alternative method, namely the baroreceptor stimulation, has emerged; it is a novel technique aiming to stimulate the baroreceptors on the carotid wall.
The 2013 ESH/ESC guidelines for the management of arterial hypertension considered baroreceptor stimulation or renal denervation in cases of TRH [2]. The rationale for the mechanism of action of the device is the parasympathetic activation and denervation of sympathetic overactivity, which plays a role in occurrence of TRH. The regulation of the baroreceptor reflex occurs on baroreceptors located on carotid arteries and the aortic wall that are activated by pressure-induced stretch on the vessel wall. The baroreceptors regulate sympathetic and parasympathetic tones, which control BP. In chronic hypertension, the chronically increased BP inhibits the baroreceptor response (baroreceptor resetting) and causes a newly defined threshold for baroreceptor activation [4].

The currently designed device (BAROSTIM NEO System; CVRx, Inc., Minneapolis, MN, USA) activates the carotid sinus through the carotid wall. The device was validated in animal studies, followed by the European multicentric studies. The most striking feature was the 21/12, 30/20, $33 / 22 \mathrm{~mm} \mathrm{Hg}$ BP decline noted at 3 months, 1 year and 2 years respectively [4]. Most recently, in 2012, it was documented that a 26/12 $\mathrm{m} \mathrm{Hg}$ decline was noted at 6 months in TRH patients and the safety profile was similar to that of a pacemaker [5]. However, there are no data on downregulation of the chronically activated baroreceptor. A French trial which compares the efficacy with medical treatment alone has just begun.

Similar to the sympathetic and parasympathetic balance in TRH, sympathetic activation and parasympathetic denervation in HF occurs, which lead to refractory symptoms. This imbalance on the heart, blood vessels and kidneys lead to pathological left ventricular remodeling, vasoconstriction and water and salt retention respectively. The success of adrenergic blockade on HF symptoms is the rationale for baroreceptor activation therapy in these patients. Gronda et al. [6], in a small single-center, open arm study, reported an increase in quality of life score and 6-minute walking distance, improvement in NYHA class as well as decreased sympathetic activity via peroneal nerve microneurography. Soon after, in a larger study, Abraham et al. [6] documented the results of BAT in HF patients. They randomized patients with an EF of $<35 \%$ and NYHA III to GDMT alone or with BAT. The distance walked in $6 \mathrm{~min}$, quality of life score and NYHA class ranking were improved. Also, hospitalization time was reduced and $\mathrm{N}$-terminal probrain natriuretic peptide levels were decreased. The BAT had a safety profile similar to that of a pacemaker in TRH patients. It also did not produce hypotension in normotensive patients.

\section{Conclusions}

Baroreceptor activation therapy seems to be a promising therapeutic option in cases of TRH and HF. It regulates the autonomic balance and most importantly it has a safety profile similar to that of a pacemaker. We have successfully employed BAT in two patients, one with TRH and one with $\mathrm{HF}$, and documented an improvement. 


\section{Disclosure}

The authors report no conflict of interest.

\section{References}

1. Rimoldi SF, Messerli FH, Bangalore S, Schrerrer U. Resistant hypertension: what the cardiologist needs to know. Eur Heart J 2015; 36: 2686-2695.

2. Mancia G, Fagard R, Narkiewicz K, Redon J, Zanchetti A, Bohm M, Christiaens T, Cifkova R, De Backer G, Dominiczak A, Galderisi M, Grobbee DE, Jaarsma T, Kirchhof P, Kjeldsen SE, Laurent S, Manolis AJ, Nilsson PM, Ruilope LM, Schmieder RE, Sirnes PA, Sleight P, Viigimaa M, Waeber B, Zannad F, Redon J, Dominiczak A, Narkiewicz K, Nilsson PM, Burnier M, Viigimaa M, Ambrosioni E, Caufield M, Coca A, Olsen MH, Schmieder RE, Tsioufis C, van de Borne P, Zamorano JL, Achenbach S, Baumgartner H, Bax JJ, Bueno H, Dean V, Deaton C, Erol C, Fagard R, Ferrari R, Hasdai D, Hoes AW, Kirchhof P, Knuuti J, Kolh P, Lancellotti P, Linhart A, Nihoyannopoulos P, Piepoli MF, Ponikowski P, Sirnes PA, Tamargo IL, Tendera M, Torbicki A, Wijns W, Windecker S, Clement DL, Coca A, Gillebert TC, Tendera M, Rosei EA, Ambrosioni E, Anker SD, Bauersachs J, Hitij JB, Caulfield M, De Buyzere M, De Geest S, Derumeaux GA, Erdine S, Farsang C, Funck-Brentano C, Gerc V, Germano G, Gielen S, Hal- ler $\mathrm{H}$, Hoes AW, Jordan J, Kahan T, Komajda M, Lovic D, Mahrholdt H, Olsen MH, Ostergren J, Parati G, Perk J, Polonia J, Popescu BA, Reiner Z, Rydén L, Sirenko Y, Stanton A, Struijker-Boudier H, Tsioufis C, van de Borne P, Vlachopoulos C, Volpe M, Wood DA. 2013 ESH/ESC guidelines for the management of arterial hypertension: the Task Force for the Management of Arterial Hypertension of the European Society of Hypertension (ESH) and of the European Society of Cardiology (ESC). Eur Heart J 2013; 34: 2159-2219.

3. Abraham WT, Zile MR, Weaver FA, Butter C, Ducharme A, Halbach M. Baroreflex activation therapy for the treatment of heart failure with a reduced ejection fraction. ACC Heart Fail 2015; 3: 487-496.

4. Courand PY, Feugier P, Workineh S, Harbaoui B, Bricca G, Lantelme P. Baroreceptor stimulation for resistant hypertension: first implantation in France and literature review. Arch Cardiovasc Dis 2014; 107: 690-696.

5. Hoppe UC, Brandt MC, Wachter R, Beige J, Rump LC, Kroon AA, Cates AW, Lovett EG, Haller H. Minimally invasive system for baroreflex activation therapy chronically lowers blood pressure with pacemaker-like safety profile: results from the Barositm neo Trial. J Am Soc Hypertens 2012; 6: 270-276.

6. Gronda E, Seravalle G, Brambilla G, Constantino G, Casini A, Alsheraei A, Lovett EG, Mancia G, Grassi G. Chronic baroreflex activation effects on sympathetic nerve traffic, baroreflex function, and cardiac haemodynamics in heart failure: a proof-of-concept study. Eur J Heart Fail 2014; 16: 977-983. 